\title{
How virtuous is humor? Evidence from everyday behavior*
}

\author{
URSULA BEERMANN and WILLIBALD RUCH
}

\section{Abstract}

Historical as well as contemporary writers across many disciplines have referred to humor as a virtue. However, in psychological research it is not clear in which ways humor can serve (as) a virtue, and for which virtues this holds. The current study addresses this issue from the perspective of lay people's everyday lives. The aims of the study are to investigate (1) how often people achieved each of six core virtues identified by Dahlsgaard et al. (2005) by means of humor, also in relation to how important the respective virtue was for the participants, (2) to collect reports of situations where participants actually used humor to achieve any of the six virtues, and (3) to study the use of eight comic styles (Schmidt-Hidding 1963) within the reported situations. Whereas justice and humanity were the virtues considered most important, the virtues most compatible with humor seemed to be humanity and wisdom. However, it was possible to report situations for each of the virtues. More benevolent comic styles were used more frequently to achieve virtue than more malevolent styles. But whenever malevolent styles, like sarcasm or cynicism, were used, this was disproportionally often the case in order to exert justice.

Keywords: Virtue; humor; positive psychology; comic styles; situations.

\section{Introduction}

There are numerous theories and conceptions of the sense of humor and its function (e.g., Martin 2007; Ruch 2004, 2007). Most commonly humor is conceptualized as a temperament (Ruch 2002). Not surprisingly, 
psychologists as well see humor mostly as a temperament or personality trait. But humor is also considered a mood, frame of mind, talent, or a virtue (Ruch 2002). This latter notion of humor as a virtue can be found in historical as well as contemporary philosophical and theological literature. Despite the prevalence of this notion, psychological research has not paid much attention to humor as a virtue.

Positive Psychology has adopted the concept of virtues and character strengths into psychological research. These are seen as the "inner" determinants of the good life and life satisfaction (e.g., Peterson and Seligman 2004; Seligman 2002). As one of the character strengths, humor is among those related to life satisfaction most strongly (Peterson, et al. 2007: 152). However, it is neither entirely clear which aspects or facets of humor can function as virtues or serve other virtues, nor in which ways this could happen.

\subsection{Humor as virtue}

In the 18th century, humanists treated humor as a cardinal virtue. Shaftesbury (1671-1713) considered humor (or "good humour") a benevolent, tolerant form of laughter that denotes the sovereign attitude of exposing oneself to the criticism and mockery of others - to a "test of ridicule" (Schmidt-Hidding 1963: 108). As Ruch summarized, "While one should not poke fun at those who were simply odd, it was permissible to laugh at the pompous, the unreal, the faked, or the conceited" (2004: 586). "Humor" was then distinguished from other elements of the comic, such as wit, fun, or ridicule (Schmidt-Hidding 1963). Also within the Christian church, certain traditions were open to humor. According to Gilhus (1997: 73), in Gnostic myths comic techniques were vehicles to bring forth knowledge (gnosis).

More contemporary writers refer to humor as being virtuous as well. According to Comte-Sponville (2001: 211-215), for example, humor allows one to feel less self-important and thus leads to humility. Cox found that the only possibility to make sense of a traditional religion is with a playful stance toward it (as cited in Gilhus 1997: 113-114). This playful stance has its basis in the opposition between critical thinking and traditional belief, which may be contradictory. "If [the comic style of the theology of juxtaposition] therefore refuses to trim the symbol to fit the situation because it sees that, precisely in the bizarre conjoining of 
the two, both symbol and situation break open to disclose newer and richer perceptions of reality" (1969: 132). Davies (2006) suggested that many jokes indicate virtue by mocking and reproving those who lack virtue. The context in which the jokes are told, however, might be relevant for their function in communication. Jokes used as glosses in conversations might convey a critical message, advocate a course of action, support a friend or serve similar goals (Oring 2003: 91-92). One might conclude that these glosses can serve as virtues.

Philosophical literature only rarely provides examples of how humor served (as) a virtue. But it is possible to come up with examples of persons who act humorously in order to achieve positive effects. For instance, it is possible to comfort sad people by making a humorous remark in an act of kindness or humanity. Furthermore, Victor Frankl's (1984) conscious use of humor in concentration camps suggests a connection with transcendence (hoping to survive).

\subsection{Virtues in positive psychology}

Virtuousness is generally seen as acting morally, humanely, or benevolently (e.g., Comte-Sponville 2001). Yearley (1990: 13) defines virtue as "a disposition to act, desire and feel that involves the exercise of judgment and leads to a recognizable human excellence or instance of human flourishing" (1990: 13). In philosophy and in other disciplines, several virtue catalogues exist. To synthesize these, Dahlsgaard et al. (2005: 205) reviewed historical texts stemming from different cultures and religions and named six broad virtues they claimed to be universal. For Peterson and Seligman (2004) these six virtues are associated with various character strengths. The virtues are wisdom (which is associated with cognitive strengths referring to gaining and using knowledge for good purposes; character strengths involved are, e.g., judgment, love of learning, or perspective), courage (including emotional strengths concerning the will to achieve goals in the face of external or internal opposition; e.g., authenticity, bravery, or perseverance), humanity (interpersonal strengths involved in relating to others in a kind, empathetic, and benevolent way; i.e., kindness, love, or social intelligence), justice (involving civic strengths that form the basis of a healthy community life, i.e., fairness, leadership, or teamwork), temperance (strengths which master excess; e.g. forgiveness, 
humility, or self regulation), and transcendence (strengths that affect connections to the larger universe and provide meaning; e.g., hope, spirituality, or humor) (Peterson and Seligman 2004: 29-30).

\subsection{Virtues and facets of humor}

The question arises whether all virtues are served equally well by all forms of humor or whether certain comic styles are more conducive to certain virtues but not appropriate for others. Humor has often been treated as an umbrella term for everything that is funny. However, with different underlying emotions, it is possible that humor has different "flavors" (cf. Ruch 1995, 2001; Milner Davis 2003). For instance, pure farces may shift their simple, robust fun either towards romantic sentimentalism, towards bitter, black, existential angst or towards other satirical ends (Milner Davis 2003: 16). Similarly, Condren et al. (2003: 403) remark that some examples of satire are so bleak they are scarcely even humor. Schmidt-Hidding (1963) differentiated humor from other forms of the funny and suggested that humor (in the sense of an understanding for the incongruities of the world) is based on a sympathetic heart, whereas wit, for example, is based on a superior intellect. Thus, it is also conceivable that humor differs with different underlying virtues.

By consulting literature from antiquity and analyzing the modern language of humor, Schmidt-Hidding derived eight different comic styles, which received much attention in German humor literature, namely humor (in its narrow sense), wit, irony, satire, fun, nonsense, sarcasm, and cynicism (1963: 50-51). In 2001, Ruch found that SchmidtHidding's comic styles were located in a two-dimensional space with one factor covering affective/motivational elements (good humor vs. bad humor or benevolence vs. malevolence) and one factor covering mental/ cognitive elements. Regarding the "affectivity" factor, the comic styles fun, humor and nonsense were located nearer the pole "good humor" (or benevolent humor, "laughing with"; Ruch 2001: 412-413). Wit was located rather in the middle between the two poles, and irony (as the mildest form among those four), satire, cynicism and sarcasm were located nearer the pole "bad humor" (or skeptical, malevolent humor, "laughing at"; Ruch 2001: 412-413). In terms of virtue, this would lead to the assumption that the more benevolent a comic style, the more often it is used to show a virtue, and the other way round. 
However, one might argue that the malevolent comic styles also have the potential to serve certain virtues. For example, some authors referred to the use of derisive, skeptical comic styles such as satire, sarcasm, or cynicism as a social corrective. Schmidt-Hidding proposed that mockery is based on a moral sense, and for him satire aims to decry the bad and foolish, and at the general "betterment of the world" (German: Weltverbesserung, Schmidt-Hidding, 1963: 50). Similarly, Davies assumed that jokes, in their common canned form, can indicate moral failure (2006), but he doubted that they are a good method of inciting moral indignation. But spontaneous "skillful and witty put-downs can be used to ridicule, control and even express moral criticisms of human weaknesses otherwise best left unadmonished" (Davies 2002: 204). Thus, while, in general, the skeptical styles are rarely used for a positive purpose and may be hurtful, they might be employed quite frequently in context of the virtue of justice. Thus, a collection of situations in which lay people describe how they acted virtuously through the use of humor should also ask what comic style was employed. This way it is possible to study whether or not the eight comic styles of Schmidt-Hidding will be affiliated with different virtues.

\subsection{The present study}

The present study addressed the question if, to what extent, and how virtue can be achieved by humor using people's everyday experiences. The study was based on the six virtues found to be universal by Dahlsgaard et al. (2005), namely wisdom, courage, humanity, justice, temperance, and transcendence. On this basis, the aim of the present study was threefold. First, it was of interest how often people exert virtues humorously (based on self-reports by the participants) and whether or not certain virtues are expressed humorously more often than others. Such a study needs to take into account that someone who does not consider a virtue important presumably does not show it often, humorously or otherwise. Thus, as an anchor a judgment of the importance of a particular virtue were also assessed, both concerning the participants themselves and people in general.

The second aim was to collect as many examples as possible for any of the six virtues that were achieved through humorous behavior. Here, the 
"feasibility" of exerting virtue humorously was addressed. In particular, in the current study, the frequency of incidents was of interest. And third, the use of eight comic styles (Schmidt-Hidding 1963) within humorouslyexerted virtue situations was studied. It was expected that more benevolent styles (i.e., humor in the narrow sense, fun, wit, nonsense; Ruch 2001) occur more frequently than more skeptical ones. Furthermore, if skeptical, derisive comic styles (in particular sarcasm, cynicism, or satire) were used, participants were expected to apply them disproportionately often in justice-related situations.

\section{Method}

\subsection{Participants}

The sample consisted of $N=48$ German-speaking participants (18 males and 30 females) between 25 and 88 years of age $(M=47.67, S D=18.80)$ from Switzerland, Austria, and Germany. Among them, the education level of 6 participants was a completed apprenticeship, 13 participants had a general qualification for university entrance, and 27 participants had a university degree. Two participants did not specify their level of education.

\subsection{Instrument}

The Humor in Tugenden questionnaire (humor in virtues, HiT) was developed for the current study to assess humorous events that simultaneously served a certain virtue. It consists of two parts. Part A addresses four ratings concerning the attitude to virtue, and to virtue and humor. Part B allows for reporting incidents and for assigning comic styles that participants had used in these incidents. Both parts are organized by the six core virtues identified by Dahlsgaard et al. (2005). In order to counteract sequence effects, two parallel versions of the HiT with reversed sequences of the six virtues exist.

Part A assesses the attitude to the six virtues wisdom, courage, humanity, justice, temperance, and transcendence. For every virtue, a definition 
according to Peterson and Seligman (2004) is provided together with a list of those of the 24 character strengths that are hypothesized to lead to the respective virtue. This is followed by four ratings: (1) How do you evaluate the role of virtue $X$ in daily human interaction? (rated "importance"; bipolar 7-point rating scale from $-3=$ "extremely obstructive" via $0=$ "neither obstructive nor beneficial" to $3=$ "indispensable"), (2) How much do you feel committed by virtue X? (rated "commitment"; 5-point Likert-scale from $1=$ "not at all" to $5=$ "very much"), (3) In everyday life, people are sometimes serious and sometimes humorous. This is also the case in situations where virtues occur. When considering all situations in which the virtue $X$ is shown: In how many of them is this done in a humorous way? (rated "employment, general"; the frequency has to be estimated; $0=$ "never" to $100=$ "always"), and (4) How often have you been able to exert the virtue $X$ in a humorous way? (rated "employment, self"; 5-point Likert-scale from $1=$ "never before" to $5=$ "nearly always").

Part B of the questionnaire aims to collect actual scenarios from everyday life in which each of the six virtues mentioned above was achieved in a humorous way. For each of the virtues, the instruction is designed to help the participants to either remember situations where they themselves were the acting persons showing the respective virtue humorously, or where they witnessed another person doing so, or situations which they have been told by someone else, seen on television, read in a book, or just can imagine. These remembered or visualized situations have to be written down as accurately as possible. In order to facilitate recall and to obtain as detailed descriptions as possible, questions concerning details of the situations are integrated into the instruction (i.e., Where did the situation take place? Who was there? What caused the situation, what was going on, how did it end?). Furthermore, questions regarding the virtuous and the humorous aspects of the situations are added (i.e., What in particular was the virtuous act? Which humorous behavior has been shown that helped to exert the virtue?). For the current study, the frequencies of the situations rather than the actual contents were of interest.

Additionally, for each situation provided the participants were asked to choose one or more of eight comic styles according to Schmidt-Hidding (1963), which they thought was used in a given situation. The comic styles were the following: Humor (in the sense of appreciation of the world's inconsistency and arousing sympathy), wit, irony, satire, fun, nonsense, sarcasm, and cynicism. 


\subsection{Procedure}

The participants received the questionnaire via email or postal mail. Each parallel version of the HiT was answered by half of the participants. The participants filled in Part A by themselves at home. However, they were allowed to exchange thoughts with their family or friends regarding Part $B$. This should facilitate the relatively complex task of remembering and writing down situations in which they or somebody else was both virtuous and humorous, and thus combining two aspects in hindsight that they probably were not too aware of at the time. This procedure was chosen because the aim of Part B is not to measure any behavior but to collect as many scenarios as possible.

The participants were asked to report as many situations as possible for each virtue. They were encouraged to take their time remembering virtuous and humorous situations. However, they were reassured that it would be fine if they would not be able to cover all virtues when reporting situations. If they found that more than one virtue was realized in the situation, they were instructed to assign it to the virtue most prominent for them.

Without addressing directly how virtuous the participants actually acted, the virtue ratings assessed a general judgment concerning the role of the virtue and their commitment to the virtue (regardless of how successful the participants actually were in realizing the virtues). Even so, in order to counteract social desirability effects, it was pointed out explicitly that the aim of this study was not to find out how virtuous or how humorous the participants were, but that it was of interest if, and if so how, humor can be employed in order to realize virtue. Finally, the participants were assured that their data would be handled anonymously.

\section{Results}

\subsection{The role of virtue and humor in Part A of the HiT}

Means were computed for rated importance of and the participant's personal commitment to virtue, and the employment of humor for virtue in general and concerning themselves (Part A of the HiT). Next, differences between the six virtues were studied using one-way ANOVAs for repeated measures with the type of virtue as repeated measurement factors 
Table 1. Effects of the kind of virtue on the importance, commitment, employment general, employment self ratings, the difference between commitment and employment self and the number of situations

\begin{tabular}{|c|c|c|c|c|c|c|c|}
\hline Variable & Wisdom & Courage & Humanity & Justice & Temperance & Transcendence & Main effects \\
\hline \multicolumn{8}{|l|}{ Importance } \\
\hline$M$ & $1.89^{\mathrm{b}}$ & $1.70^{\mathrm{b}}$ & $2.24^{\mathrm{a}}$ & $2.37^{\mathrm{a}}$ & $1.83^{\mathrm{b}}$ & $1.70^{\mathrm{b}}$ & \multirow{2}{*}{$\begin{array}{l}F(5,45)=6.97 \\
p<.0001\end{array}$} \\
\hline$S D$ & 0.92 & 0.70 & 0.67 & 0.88 & 0.83 & 0.81 & \\
\hline \multicolumn{8}{|l|}{ Commitment } \\
\hline$M$ & $4.26^{\mathrm{a}}$ & $3.89^{\mathrm{b}}$ & $4.37^{\mathrm{a}}$ & $4.46^{\mathrm{a}}$ & $3.91^{\mathrm{b}}$ & $4.20^{\mathrm{a}}$ & \multirow{2}{*}{$\begin{array}{l}F(5,45)=5.70 \\
p<.0001\end{array}$} \\
\hline$S D$ & 0.77 & 0.77 & 0.83 & 0.86 & 0.84 & 0.86 & \\
\hline \multicolumn{8}{|l|}{ Employment-g } \\
\hline$M$ & $42.57^{\mathrm{a}}$ & $33.78^{b}$ & $46.59^{a}$ & $30.48^{\mathrm{b}}$ & $26.87^{b}$ & $26.69^{b}$ & \multirow{2}{*}{$\begin{array}{l}F(5,41)=12.13 \\
p<.0001\end{array}$} \\
\hline$S D$ & 24.25 & 22.08 & 22.59 & 22.13 & 18.49 & 18.68 & \\
\hline \multicolumn{8}{|l|}{ Employment-s } \\
\hline$M$ & $3.09^{\mathrm{ab}}$ & $3.00^{\mathrm{bc}}$ & $3.39^{\mathrm{a}}$ & $3.02^{\mathrm{bc}}$ & $2.80^{\mathrm{c}}$ & $2.87^{\mathrm{c}}$ & \multirow{2}{*}{$\begin{array}{l}F(5,43)=4.95 \\
p<.001\end{array}$} \\
\hline$S D$ & 0.87 & 0.71 & 0.68 & 0.72 & 0.86 & 0.83 & \\
\hline \multicolumn{8}{|c|}{ Commitment — Employment-s } \\
\hline$M$ & $1.14^{\mathrm{ab}}$ & $0.89^{b c}$ & $0.98^{\mathrm{bc}}$ & $1.43^{\mathrm{a}}$ & $1.11^{\mathrm{ab}}$ & $1.34^{\mathrm{a}}$ & \multirow{2}{*}{$\begin{array}{l}F(5,43)=3.66 \\
p<.01\end{array}$} \\
\hline$S D$ & 1.05 & 0.92 & 0.79 & 0.93 & 0.92 & 0.91 & \\
\hline \multicolumn{8}{|c|}{ Number of situations ${ }^{1}$} \\
\hline Median & 0.60 & 0.67 & 0.73 & 0.60 & 0.61 & 0.71 & \multirow{2}{*}{$\begin{array}{l}\chi^{2}(5,46)=1.71 \\
p=.89\end{array}$} \\
\hline Mean ranks & 3.40 & 3.52 & 3.74 & 3.37 & 3.30 & 3.66 & \\
\hline
\end{tabular}

Notes. Importance $=$ Importance of the role of each virtue in general; Answer format from -3 to +3 . Commitment $=$ Felt commitment to each virtue; Answer format from 1 to 5. Employment-g = Estimate of how often humor is employed for each virtue in general; Answer format from 0 to 100. Employment-s = Estimate of how often humor is employed for each virtue by participants themselves; Answer format from 1 to 5 . Commitment - Employment-s = Difference between commitment and employment, self rating. Number of situations $=$ Number of valid situations.

${ }^{1}$ Friedman's ANOVA was computed for the number of situations.

a,b,c Means of a column with same superscripts don't differ significantly at $p<.05$ (Fisher LSD).

$N=42-47$. 
for each of the four ratings as dependent variable. For significant effects, posthoc tests (Fisher LSD) were computed to locate the differences between virtues. Means, standard deviations, and the ANOVAs for each rating are presented in Table 1.

The data in Table 1 confirms that participants indeed found virtues important. Across all virtues, the mean rating was $M=1.95$ suggesting that the participants tended to judge the role of virtue as very beneficial $(=2)$. The ANOVA revealed a significant main effect for the type of virtue on rated importance. Two of the virtues, namely humanity and justice, were judged to be more important than wisdom, courage, temperance, and transcendence, which did not differ from each other.

The participants felt on average rather $(=4)$ to very much $(=5)$ committed by the particular virtue $(M=4.18)$. The ANOVA for rated commitment showed a significant main effect for the type of virtue. Here, posthoc tests yielded that the participants felt especially committed to humanity, justice, transcendence, and wisdom. The judgments for the two virtues temperance and courage followed these four and did not differ from each other. ${ }^{1}$

On average, the participants estimated that in $34.77 \%$ of all situations virtue had been shown humorously (employment, general). The ANOVA resulted in a significant main effect for the type of virtue. Humor was used most often for humanity and wisdom, followed by courage, justice, transcendence and temperance, which did not differ from each other.

The participants reported having employed humor for virtues themselves several times ( $=3 ; M=3.03)$ on average. Conducting the ANOVA for the rated employment, self yielded a significant main effect for the type of virtue. Humanity was followed by wisdom, courage, justice, transcendence, and temperance. However, whereas humanity as the highest differed from all five other virtues, wisdom did neither differ from humanity nor from courage and justice. Wisdom was exerted humorously more often than transcendence and temperance, but the latter two were not significantly different from courage and justice.

\subsection{Relations among importance and commitment to a virtue and its humorous realization}

In order to analyze how rated importance, commitment, employing humor for virtue in general and employing humor for virtue by oneself corre- 
sponded to each other, within each of the six virtues Pearson correlations for all pairs of ratings were computed. The coefficients for each rating combination are shown in Table 2.

The data in Table 2 shows that the more people thought of a certain virtue as important for human interaction (importance), the more they also felt committed to that virtue (commitment). The average correlation across all virtues was $r=.46$. The correlation was lowest for wisdom and highest for justice. Furthermore, the more people thought it is possible to achieve a certain virtue by using humor in general (employment, general), the more they reported to have done so themselves for that virtue (employment, self ). Not surprisingly, these two ratings yielded a very high mean correlation coefficient $(r=.49)$. Courage showed the lowest correlation and justice the highest. Additionally, the more people felt committed to a certain virtue (commitment), the more they also sought to exert this virtue by using humor (employment, self). There was a moderate average correlation $(r=.35)$. It was not significant for wisdom and courage, and highest for humanity. Furthermore, considering a virtue important for human interaction (importance) was only weakly related to its humorous realization by oneself (employment, self) with an average correlation of $r=.18$. There were, however, significant relationships for the virtues justice, temperance, and transcendence.

Does the use of humor generalize across all virtues? To answer this question, the intercorrelations among the six virtues were computed for rated employment, self. It turned out, that no general tendency to employ humor in virtues was found. However, the virtues were not completely independent either, rather clusters of related virtues emerged. First, people who have frequently exerted transcendence humorously, also said they have done so for temperance $(\mathrm{r}=.55, \mathrm{p}<.01)$ and wisdom $(\mathrm{r}=.49$, $\mathrm{p}<.01$ ), with temperance and wisdom yielding a correlation of $\mathrm{r}=.30$ $(\mathrm{p}<.05)$. Second, having shown humanity humorously went along with having exerted courage humorously $(r=.52, p<.01)$. And third, the realization of temperance in a humorous way by the people themselves was related to the realization of justice in a humorous way $(r=.41, p<.05)$.

Is the relationship between how important a virtue is to how often one employed humor when pursuing that virtue the same for each of the virtues? In other words, are some virtues more conducive to a humorous treatment than others? In order to answer this question, a 2 (type of rating) $\times 6$ (type of virtue) ANOVA for repeated measures was computed. The profiles are illustrated in Figure 1. 
Table 2. Pairwise correlations among the four ratings for each virtue

\begin{tabular}{|c|c|c|c|c|c|c|}
\hline \multirow[t]{2}{*}{ Virtue } & \multicolumn{3}{|c|}{$r$ of Importance with } & \multicolumn{2}{|c|}{$r$ of Commitment with } & \multirow{2}{*}{$\begin{array}{l}r \text { of Employment-g with } \\
\text { Employment-s }\end{array}$} \\
\hline & Commitment & Employment-g & Employment-s & Employment-g & Employment-s & \\
\hline Wisdom & .29 & .06 & .02 & .13 & .20 & $.55^{* *}$ \\
\hline Courage & $.36^{*}$ & -.16 & -.13 & .01 & .21 & $.32 *$ \\
\hline Humanity & $.48 * *$ & .14 & .23 & -.13 & $.45^{* *}$ & $.45^{* *}$ \\
\hline Justice & $.57 * *$ & .21 & $.34^{*}$ & $.32 *$ & $.34^{*}$ & $.56^{* *}$ \\
\hline Temperance & $.52 * *$ & .10 & $.30 *$ & .20 & $.44^{* *}$ & $.52 * *$ \\
\hline Transcendence & $.56^{* *}$ & $.37 *$ & $.33^{*}$ & .21 & $.44^{* *}$ & $.55^{* *}$ \\
\hline Average corr. & $.46^{* *}$ & .12 & .18 & .12 & $.35^{*}$ & $.49^{* *}$ \\
\hline
\end{tabular}

NoTES. Importance $=$ Importance of the role of each virtue in general. Commitment $=$ Felt commitment to each virtue. Employment-g. $=$ Estimate of how often humor is employed for each virtue in general. Employment-s = Estimate of how often humor is employed for each virtue by participants themselves.

$N=43-46$.

$* p<.05 . * * p<.01$. 


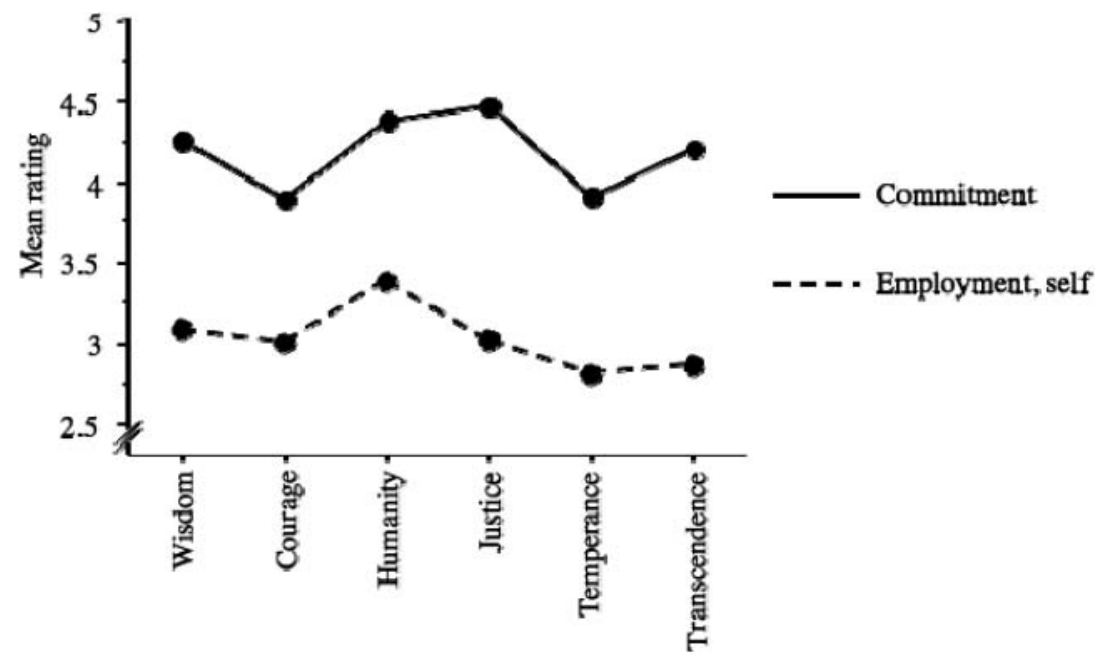

Figure 1. Mean ratings for commitment for virtue and employment of humor for virtue by oneself across the six virtues

As expected, the ANOVA revealed a significant interaction, $F(5,43)=$ $3.66, p<.01$, confirming that the frequency of the use of humor does not merely reflect the importance of the virtue (Figure 1). In order to examine which of the virtues were involved in the interaction, difference scores were calculated by subtracting the mean score for rated employment, self from the mean score of rated commitment for each virtue. A one-way ANOVA for repeated measurement was performed for the resulting six difference scores with type of virtue forming the repeated measurement factor. As posthoc tests revealed, for justice and transcendence the difference value was larger than for the other four virtues (although for temperance and wisdom, the values failed to be significantly lower; see Table 1). This means that participants, irrespective of how much they felt committed to a virtue, tended to use humor less frequently in justice and transcendence situations. In other words, humor is relatively infrequently combined with these two virtues.

\subsection{Number of situations for each virtue - Part B of the HiT}

Analysis of Part B showed that of the 48 participants, 42 reported at least one situation in total resulting in a total of 248 situations. However, not 
all situations contained the criteria the participants had been asked for or were "off-topic". For example, some of the situations represented elements of humor but no virtuous aspects, or vice versa. Thus, the first author screened all reported situations and removed the off-topic situations. This yielded 40 remaining persons providing "valid" situations. They reported a number between 1 and 18 valid situations per participant $(M d n=4.25, M A D=1.50)$ and a total of 210 situations. Per virtue, the participants described between 1 and 6 situations.

For every virtue situations were reported in which humor has been employed. In order to determine whether there were differences in the number of situations between the virtues, a Friedman ANOVA for the number of situations within the six virtues was conducted. The exact medians and the mean ranks for the number of situations for every virtue are given in Table 1. As the coefficients in Table 1 show, there was no difference; the participants reported situations for all six virtues to the same degree.

\subsection{Comic styles}

For all reported situations, the participants also assigned the situations to one or more comic styles that were used in the situations. ${ }^{2}$ In order to assess differences in the use of the comic styles, a Friedman's ANOVA ${ }^{3}$ was performed. Indeed, there were significant differences in the frequency of the styles, Friedman's $\chi^{2}(7,203)=175.01, p<.001$. The comic style used most often was humor (in the narrow sense). This was followed by fun, wit, irony, sarcasm, nonsense, satire, and cynicism, in that order.

Wilcoxon tests were calculated in order to obtain information on significant differences regarding the comic styles. A Bonferroni correction was applied. All reported effects are tested at $p<.002$. Humor and wit appeared significantly more often than satire $(T=576$ and 520 , respectively), nonsense ( $T=570$ and 513.5, respectively), $\operatorname{sarcasm}(T=768$ and 870 , respectively), and cynicism ( $T=495$ and 410, respectively, all $p<$ $.002)$. Furthermore, people applied fun and irony significantly more often than nonsense ( $T=468$ and 540, respectively), $\operatorname{sarcasm}(T=1069.5$ and 396.5, respectively), and cynicism ( $T=410$ and 150, respectively, all $p<$ $.002)$. Fun was used more often than satire $(T=637.5, p<.002)$.

In the following, the frequencies of the comic styles for every virtue were investigated in more detail. Figure 2 shows the relative frequencies of the comic styles (i.e., profiles for each comic style) for every virtue. 


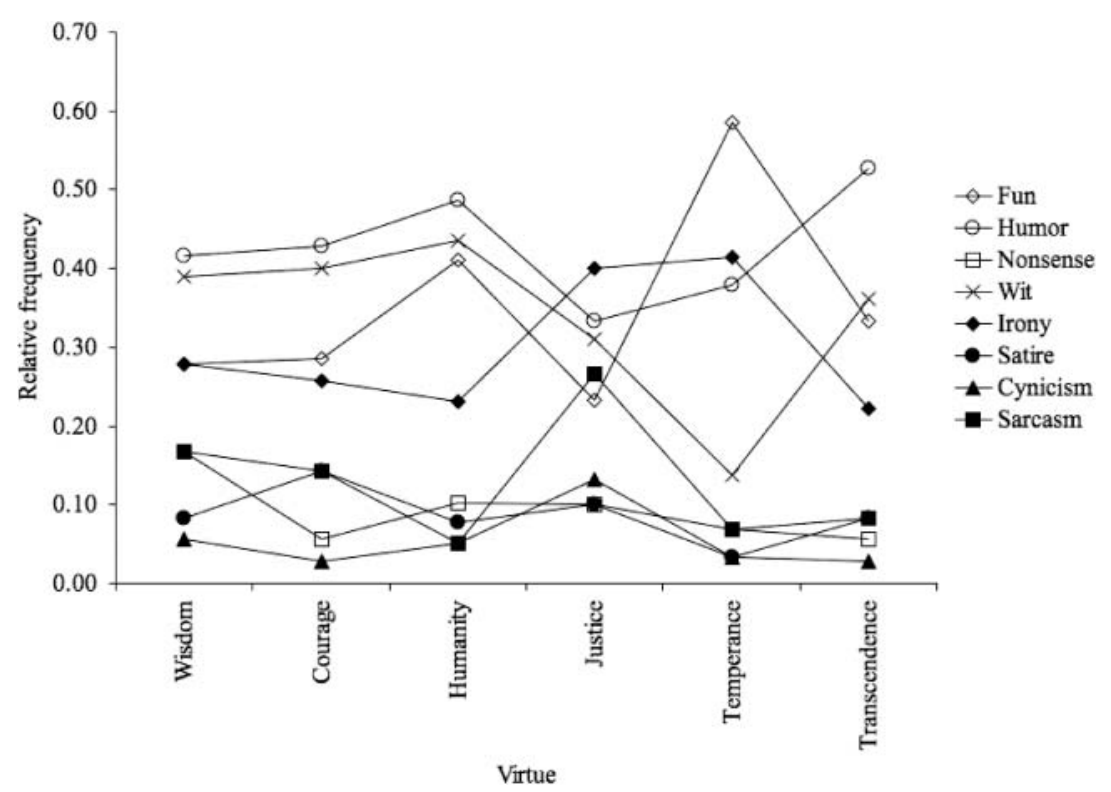

Figure 2. Profiles of the comic styles accross the six virtues

Figure 2 illustrates that, generally, the use of a specific comic style seemed to depend on the virtue that was targeted. In particular, there seemed to be much variance in fun depending on the virtue (with a minimum relative frequency of 0.23 and a maximum of 0.59 ); it was used moderately often to show wisdom, courage, or transcendence, rather often to show humanity and even more so for temperance, but less often for justice. The use of wit was rather high with the exception of temperance (the relative frequency ranged from 0.14 to 0.44 with a mean of 0.34 ). The profile of irony had a moderate level (ranging from 0.22 to 0.44 with an average relative frequency of 0.30 ). It was noticeable that the profile of irony with respect to virtue mirrored the one of humor. Especially comic styles generally regarded as more skeptical (Ruch 2001: 412-413, in particular sarcasm, irony, and cynicism) had peaks or higher values with respect to justice. However, it must be kept in mind that with respect to comic styles, multiple answers were possible. Comic styles were not entirely independent from each other. Figure 2 is intended to illustrate the differentiated use of comic styles, but does not show the different configurations among the comic styles. 
To test the hypothesis whether derisive humor was used more often in justice situations compared to the other virtues, a $\chi^{2}$-analysis was undertaken for all justice situations vs. situations for all other virtues with the frequency of dark humor (a variable aggregated from the three derisive comic styles satire, sarcasm and cynicism with 0 or 1 data) as dependent variable. The proportion of derisive humor differed significantly between justice vs. all other situations, $\chi^{2}(1)=5.39, p<.05$. Based on the odds ratio, it seems that derisive humor was used 2.57 times more often for justice situations than for situations of all other virtues.

\section{Discussion}

The current study is an attempt at addressing humor as one possible means of achieving virtue. By involving lay people, it was possible to study the use of humor for virtues based on everyday experience. Selfreports on virtue independent of humor, on virtue exerted by using humor, as well as actual examples of acting virtuously in a humorous way were assessed. Indeed, the study could show that humor can serve the entire six core virtues identified by Dahlsgaard et al. (2005). Self-reports revealed that it seems to be particularly appropriate to employ humor for humanity and wisdom. Using the performance part of the HiT, each of the virtues examples of everyday situations could be identified. Within these situations, generally benevolent comic styles were used more often. If derisive and skeptical styles were used, this was in particular the case in justice situations.

\subsection{Virtues and humor in the lay people's view}

The first goal of the study was to investigate the participants' estimates of how often people have achieved each of the six core virtues according to Peterson and Seligman (2004) in a humorous way. It revealed two virtues that seem to be exceptionally suitable for implementing them with the help of humor. These "top" (i.e., most frequently realized by humor) virtues are humanity and wisdom. One reason for this may be connected with associations people have concerning humanity and wisdom. Both seem to incorporate something like "goodwill". Helping people and being friendly is associated to smiling and making harmless jokes. Humor is a 
frequently mentioned desirable attribute of partners and thus contributes to the character strength of love. Wisdom is connected to giving good advice, which might also include advice concerning problems of other people. In movies or books, wise people are often depicted as old, benignly smiling, composed men or women, who teach their younger and still unsettled pupils in a calm and sometimes humorous way, thus realizing sereneness and smiling benevolently in the face of adversities. However, besides these associations, this is also in accordance with philosophical and theological literature. The humanists referred to (good) humor as the benevolent forms of humor (Schmidt-Hidding 1963; Ruch 2004). Schmidt-Hidding proposed that humor (as opposed to mock, wit or fun) is based on a "sympathetic heart". Similarly, Peterson considers humor to be a strength of the heart (as opposed to strengths of the mind) which is compatible with other character strengths of humanity (2006: 158). Others see humor as a way of dealing wisely with everyday life (cf. Bühler 2007; Webster 2003). By asking experts to rate the degree of the six core virtues within the contents of humor questionnaire items, Beermann and Ruch (in press) found wisdom and humanity to be the top virtues connected to humor. One might imagine a person acting humanely and wisely at the same time. But even so, employing humor for wisdom was only weakly related to employing humor to realize humanity. Thus, mostly independent from each other, both virtues seem to be highly compatible with humor.

The kind of virtue applicable for using humor doesn't seem to be entirely congruent with the kind of virtue considered most crucial. The top two virtues considered most important for daily human interactions were justice and humanity, and the top four virtues people felt committed to were justice, humanity, wisdom, and transcendence. Compared to the commitment to virtue, people seemed to use humor less for the two virtues justice and transcendence. Several explanations are possible for this result. One explanation is that it is more difficult to use humor for justice or transcendence. For example, people might have problems assuring their authority as leaders. When employing humor for leadership, they might fear that they are not taken seriously. Another possibility is that even if they would be able to apply humor for justice or transcendence, the recipient might not acknowledge this. A person who tends to suffer from gelotophobia (cf. Ruch 2009) might be irritated when he or she is rebuked in a humorous way, even when it was meant to be benevolent. Likewise, situations conveying transcendence were often connected with 
dying. Some people probably think that when dealing with death humor is not allowed, and feel affronted if someone jokes in this kind of situations. However, there are reports of seriously ill or even dying persons who wish a "normal", humorous communication with nursing staff or family and friends rather than a muted and deadly serious one in order not to feel "as if you were already buried" (e.g., Bischofberger 2002: 129).

As expected, finding a particular virtue important in general relates to feeling committed to the respective virtue. It was also predictable that people who think that virtues have been achieved humorously in general also report that they had employed humor for virtues themselves. Furthermore, feeling committed to a virtue was related to exerting it humorously for four of the virtues. Feeling committed to wisdom or courage, however, does not relate highly to applying humor in order to exert these two virtues. What is the difference between wisdom and courage and the other four virtues? It seems that the difficulty in achieving different virtues varies. For example, wisdom might be connected to cognitive strengths, such as intelligence, so that some people might find it difficult to "choose" to act wisely - as compared to, for example, humanity, where you can more easily choose to be friendly, or temperance, where you can more easily choose to moderate yourself. Also, courage might be difficult for some people who, for example, have higher degrees of anxiety. Thus, it might be possible that the more difficult a virtue putatively is, the less opportunities existed where the respective virtue could be shown, and especially in a humorous way - but only for a part of the participants. That is, in addition to how difficult it is to realize a virtue humorously, for these two virtues it might be difficult to show it at all, that is, humorously or non-humorously - as it was not asked how often participants succeeded in showing virtue independently from humor.

\subsection{Examples of humorous and virtuous behavior - the collected situations}

The second goal was to collect examples of the participants' lives where they actually employed virtue in a humorous way. This was done in order to check for the "feasibility" of doing this. Indeed, it is possible to report a considerable number of situations in which humor has been employed for each of the six virtues. More than $80 \%$ of the participants found and 
remembered ways of using humor to achieve virtue. Most of the examples were detailed and it was possible to get a good impression (some of the descriptions had more than 400 words). This was possible in spite of the complexity of the task. People had to remember situations that theyretrospectively and possibly for the first time ever - had to evaluate as virtuous (and assign to a certain virtue), and which contained humorous behavior that was aimed at achieving virtue. In addition, a talent in writing has an influence on the number of reported situations. This performance aspect might also have influenced that, in contrast to the self-reports, there is no significant difference in the number of situations reported per virtue.

\subsection{What kind of humor? - The comic styles}

The third goal was to study (self-reported) linguistic comic styles that were used in order to apply humor to achieve virtue. The analyses regarding the use of comic styles revealed that any comic style was used in the situations to achieve virtue. However, the rank order of the frequency of use of the styles roughly corresponded to Ruch's (2001) findings on the location of the comic styles on the "good humor" vs. "bad humor" factor. That is, benevolent comic styles were in general exploited more often in the virtue situations than malevolent styles. Only irony and nonsense seemed to have changed sides. Irony was among the four comic styles used more often - along with three benevolent styles, whereas nonsense was among the four styles used least in the reported situations. As irony is milder and not as "aggressive" as the other skeptical styles, it seems plausible to use it more often in context of virtue. Since the content of nonsense is absurd and literally does not make sense, nonsense does not necessarily seem to have a function with respect to virtue (see also Ruch and Hehl 1987). Thus it seems understandable that an application with any virtue as a purpose is not easily possible.

However, the analyses of the different comic styles revealed that in comparison to other virtues, more skeptical, "laughing at" comic styles such as satire, cynicism or sarcasm were used in order to achieve justice. This result is in accordance with Schmidt-Hidding, who proposes that mock and ridicule are based on moral sense (1963: 48), and Long and Graesser, who proposed the use of sarcasm or satire in order to enforce social norms (1988: 53-54). 
The following example illustrates a situation where sarcasm was used to exert justice.

About 40 years ago, when I was a student I had a summer job as a waiter in a hotel. The boss was extremely tough and dealt with the employees as if they were pieces of wood. Especially female foreign seasonal labors were exploited wherever possible (14 hours of work with only one break, which was already before midday after only two hours of work, and during which they had to clean the bedrooms of their male colleagues - the waiters) and often were fired because of the smallest "misdoings". When again a whole series of "sackings" had happened, I was seething with rage about this injustice and xenophobia. But because I didn't dare stand up to it openly, I started humming the melody of "Zehn kleine Negerlein" (An outdated children's song to the tune of "Ten Little Indians", containing ten verses in each of which one boy dies or "disappears", A/N) while I was cleaning the lounge - loud enough for my boss to hear it. She snarled at me asking what I was singing, and I told her defiantly. She left without another word. - It was due to an older waiter that I wasn't fired after this incident; he told me later that he had spoken to her on my behalf. Here the "humor" of the song served as a vehicle for standing up for justice in a hidden way, because I didn't dare do it openly.

The situation exemplifies a hard situation involving a high degree of injustice (although also courage was probably needed in this situation). The participant described how (self-reported) sarcasm helped him to express his disapproval of his boss' exploitative and xenophobic behavior.

Above, several possible explanations were discussed why justice has been shown less often in a humorous way than what could be expected when considering the high commitment to it. If skeptical styles were used disproportionately often in justice situations, this might be an additional explanation for the reduced frequency of justice and humor. Not everybody is able or ready to use skeptical comic styles.

Of course, not all justice situations involved sarcasm. For example, one participant described how she achieved justice among children pushing around a toy. She settled a dispute among them by imitating their behavior in an exaggerated, funny way, which made the children laugh and pay more attention to all children being able to play with it. The comic style she identified in this situation was fun.

The following examples illustrate how further comic styles were used in order to exert virtues. One participant provided the following transcendence situation as an example for the comic style humor (in its narrow sense). She reported how her grandmother, when she was about to die, had planned the funeral together with the priest and her family including 
the guest list and funeral oration. She had intended to "make it a nice day, since all family and friends were meeting there." According to the participant, on the funeral day there was indeed a lot of laughter, thus the grandmother had succeeded in planning an event in the way she wanted it to be transcending her own death. An example for wit and irony is given in a situation reported for the virtue temperance. The participant described a friend moving into her tiny room in her accommodation during a weekend workshop, and reducing her demands concerning the size of motel rooms by commenting that luxury doesn't make one happy anyway.

There are, of course, limitations to the study. The analyses were restricted to self-reports of comic styles. However, there was a considerable agreement between the comic styles self-reported by the participants and those coded by an expert for 40 of the situations. This agreement has been found in spite of the fact that the expert was not present in the actual situations (and thus only had the reports varying in veracity with the writing abilities of the participants). It is necessary to replicate the link between skeptical comic styles and justice. Furthermore, there might be further humor styles that were not included in the present list.

Nevertheless, the current study was able to show that humor can be a way of implementing virtue. It yielded a pool of situations covering six universal virtues. It focused on the general feasibility and analyzed the comic styles used in the situations. Based on this study it is now possible to extract more detailed facets on how each virtue can be realized. Similary, the causality is not always clear: does a person exert wisdom in a humorous way, or does a person use humor in a wise and tactful way? This corresponds to Aristotles' view on humor, summed up by Morreall: "The virtue of engaging in humor to the right degree, and at the right time and place, Aristotle called eutrapelia, ready-wittedness" (2008: 218). Both directions might be possible and should be investigated based on the examples collected in this study.

University of Zurich

\section{Notes}

Correspondence address: u.beermann@psychologie.uzh.ch

* The authors wish to thank Christian F. Hempelmann and René T. Proyer for helpful comments on prior versions of the manuscript. 
1. Within the commitment rating, and only here, there were gender differences, $F(1,44)=$ $5.07, p<.05$. Females rated their commitment to virtue higher than males (Fisher LSD).

2. A researcher familiar with the terminology by Schmidt-Hidding (1963) served as expert and coded 40 of the collected situations for the comic styles. The agreement between the expert and the participants was .64.

3. For dichotomy data like these, usually a Cochran's Q analysis is performed. However, the Friedman's $\chi^{2}$ had exactly the same power as the Cochran's Q and provided mean ranks which was more appropriate for describing the results.

\section{References}

Beermann, Ursula \& Willibald Ruch. In press. How virtuous is humour? What we can learn from current instruments. Journal of Positive Psychology.

Bischofberger, Iren. 2002. "Das kann ja heiter werden." Humor und Lachen in der Pflege ["That sounds like fun." Humor and laughter in care]. Göttingen: Hans Huber.

Bühler, Pierre. 2007. Ethik des Alltäglichen [Everyday ethics]. Berliner Theologische Zeitschrift 24(2). 278-288.

Comte-Sponville, André. 2001. A short treatise on the great virtues: The uses of philosophy in everyday life. New York: Metropolitan Books.

Dahlsgaard, Katherine, Christopher Peterson \& Martin E. P. Seligman. 2005. Shared virtue: The convergence of valued human strengths across culture and history. Review of General Psychology 9(3). 203-213.

Davies, Christie. 2002. The mirth of nations. New Brunswick: Transaction Publishers.

Davies, Christie. 2006. Virtue, Aristotle, and popular culture. Unpublished ms., University of Reading.

Frankl, Viktor E. 1984. Man's search for meaning. New York: Washington Square Press.

Gilhus, Ingvild Sælid. 1997. Laughing gods, weeping virgins. London: Routledge.

Long, Debra L. \& Arthur C. Graesser. 1988. Wit and humor in discourse processing. Discourse Processes 11(1). 35-60.

Martin, Rod A. 2007. Psychology of humor: An integrative approach. Burlington, MA: Elsevier Academic Press.

Milner Davis, Jessica. 2003. Farce. 2nd edn. New Brunswick, NJ: Transaction Publishers.

Morreall, John. 2008. Philosophy and religion. In Victor Raskin (ed.), The primer of humor research, 211-242. New York \& Berlin: Mouton de Gruyter.

Oring, Elliott. 2003. Engaging humor. Urbana \& Chicago: University of Illinois Press.

Peterson, Christopher. 2006. A primer in positive psychology. New York: Oxford University Press.

Peterson, Christopher \& Martin E. P. Seligman. 2004. Character strengths and virtues: A classification and handbook. New York: Oxford University Press.

Peterson, Christopher, Willibald Ruch, Ursula Beermann, Nansook Park \& Martin E. P. Seligman. 2007. Strengths of character, orientations to happiness, and life satisfaction. Journal of Positive Psychology 2(3). 149-156.

Ruch, Willibald. 1995. A psycholexical study of the "sense of humor": Taxonomizing German humor-related nouns. Paper presented at The Thirteenth International Humor Conference, Birmingham, July 31-August 4.

Ruch, Willibald. 2001. The perception of humor. In Alfred W. Kaszniak (ed.), Emotion, qualia, and consciousness, 410-425. Tokyo: Word Scientific Publisher. 
Ruch, Willibald. 2002. State of the art in humour research. Presidential address of the 21st International Humor Conference and the 14th Conference of the International Society for Humor Studies, Forli, Italy.

Ruch, Willibald. 2004. Humor (playfulness). In Christopher Peterson \& Martin E. P. Seligman (eds.), Character strenghts and virtues: A classification and handbook, 583-598. New York: Oxford University Press.

Ruch, Willibald. 2007. The sense of humor: Explorations of a personality characteristic (Mouton Select). Berlin \& New York: Mouton de Gruyter.

Ruch, Willibald (ed.). 2009. Fearing humor? Gelotophobia: The fear of being laughed at. [Special issue.] Humor: International Journal of Humor Research 22(1-2).

Ruch, W. \& Franz J. Hehl. 1987. Personal values as facilitating and inhibiting factors in the appreciation of humor content. Journal of Social Behavior and Personality 2(4). 453-472.

Schmidt-Hidding, Wolfgang. 1963. Europäische Schlüsselwörter. Band I: Humor und Witz [European key terms. Volume I: Humor and wit]. Munich: Huber.

Seligman, Martin E. P. 2002. Authentic happiness: Using the new positive psychology to realize your potential for lasting fulfillment. New York: Free Press.

Webster, Jeffrey D. 2003. An exploratory analysis of a self-assessed wisdom scale. Journal of Adult Development 10(1). 13-22.

Yearley, Lee H. 1990. Mencius and Aquinas: Theories of virtue and conceptions of courage. Albany: State University of New York Press. 